\title{
A Study on Design and Application of Dynamic Planning Model to Business Operation of Commercial Banks in China
}

\author{
ZHE Gui-chang ${ }^{1, a}$ XU Wen-juan ${ }^{2}$ \\ ${ }^{1}$ Mail box no.1910, School of Economics and Management of Yunnan Normal University, No.1 \\ Yuehua Area, Chenggong District, Kunming 650500, Yunnan Province, P. R. China \\ ${ }^{2}$ MBA Education Center, Yunnan Normal University, 298 one two one street, Kunming 650092, \\ Yunnan Province, P.R.China \\ ajcyzhegc@ynnu.edu.cn
}

Keywords: commercial banks, dynamic planning, model, exploration

\begin{abstract}
As china's finance industry has been completely opened up to the world, the industry itself is facing more and more intense competition both domestically and internationally. How can commercial banks in China allocate resources efficiently, and, meanwhile, maximize profit and minimize cost? All these questions are worth careful study. This paper intends to explore how to optimize the decision-making process of commercial bank at different stages of its business operation by designing and applying the dynamic planning model.
\end{abstract}

\section{Introduction}

Commercial banks in China are facing different kinds of decision-making choices in their daily business operation. Decision Making can be regarded as the process resulting in the selection of a course of "best" action among several alternative scenarios. From the point of view of Management, one single decision-making model consists of three basic elements: the first one is State of Nature. The aggregation of all the states is Space of State. The second is one Policy, which refers to the actions available to take. The aggregation of all the actions is called Space of Policy. The third one is Profit and Loss, which refers to the income and loss gained from different actions taken by decision makers. It is the function of Policy and State, and as well the objective and foundation of decision-making.

Commercial banks may encounter various types of decision-making. By the standard of decision level, there are strategic decision (top-level decision), tactical decision (middle-level decision), and operational decision (fundamental decision). By the standard of number of objectives, there are single-objective decision and multi-objective decision. By the standard of number of decision-making stages, there are single-stage decision (one-time decision-making) and multi-stage decision (multiple decision-making). By the standard of certainty and accuracy of information, there are risk-certain decision, risk-uncertain decision, and risk-discrete decision.

I. Procedures of creating dynamic planning equation of multi-stage decision-making for business operation of commercial banks in China

1. Correctly identify different stages of business operation of commercial banks, and define the stage-variant $\mathrm{k}$.

2. For each single stage, decide the state-variant $X_{k}$. The state-variant being chosen should meet two requirements: first, it can accurately describe the characteristics of the state of development during the whole control process; second, it should not result in after-effect that once the state of one stage is defined, development after this stage will not be affected by previous stages and previous decisions. This is also called the future-and-past-irrelevant principle.

3. For each stage of business operation, assign the decision-variant $\mathrm{U}_{\mathrm{k}}$.

4. List the transferring equation of the state of development of each neighboring-stage, $\mathrm{X}_{\mathrm{k}+1}=\mathrm{T}_{\mathrm{k}}$ $\left(\mathrm{X}_{\mathrm{k}}, \mathrm{U}_{\mathrm{k}}\right)$.

5. List the criterion function of each stage, $\mathrm{V}_{\mathrm{k}}, \mathrm{n}$.

II. Two alternative recursive models available for business operation of commercial banks

Since by nature, commercial banks belong to the category of business corporation, they have two 
objectives to achieve through business operation: one is profit maximization and the other is cost minimization. However, these two objectives are different from each other under specific decisions to make. In general, profit maximization applies to the circumstances when banks are aware of actual situation and the best result to be achieved at certain point of time in the future. In essence, it means that decision makers know the present and predict the future. Cost minimization, instead, is to define the best result to achieve in the future based on current situation, and then to decide what should be done at each stage. In essence, it means that decision makers know the future and predict the present. In real life, this method is applied to concepts such as cost rate, expense rate, and rate of bad debt and so on. Based on real-life scenarios, this paper proposes two kinds of recursive models.

1. Positive-sequence recursive model under the objective of profit maximization of commercial banks.

If the state of the initial stage $\mathrm{x}_{1}$ is given, then the model can be constructed by using positive-sequence recursion. We define $f_{k}\left(x_{k}\right)$ as the initial state $x_{k}$ of the stage of $k$. The optimal criterion function from the stage of $\mathrm{k}$ to the last stage can be defined as:

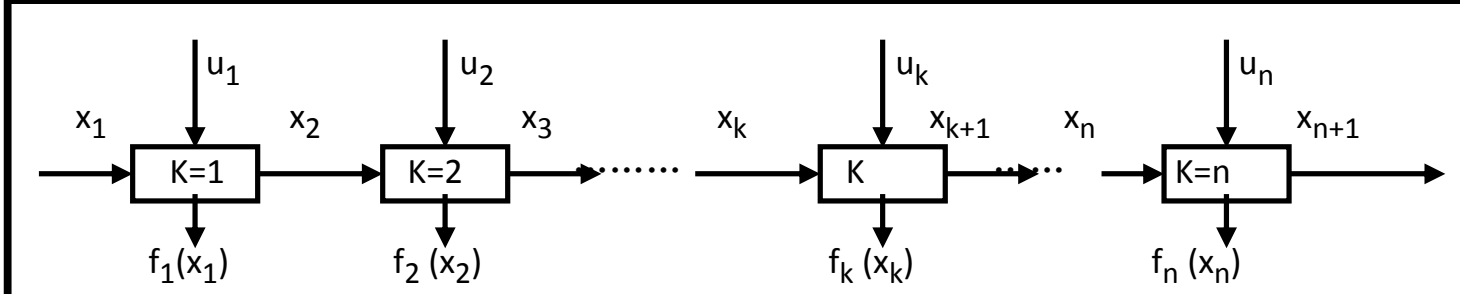

Graph 1. The positive-sequence recursive model of dynamic planning under the objective of profit-maximization of commercial banks

In general, based on real-life scenarios, $\mathrm{f}_{\mathrm{n}+1}\left(\mathrm{x}_{\mathrm{n}+1}\right)$ is the already-known boundary condition. If profit of commercial banks has reached its maximum point (cannot go higher), then $f_{n+1}\left(x_{n+1}\right)=0$. The dynamic planning equation of profit maximization of commercial banks is:

$$
\left\{\begin{array}{l}
f_{k}\left(x_{k}\right)=\max \left[g_{k}\left(u_{k}\right)+f_{k+1}\left(x_{k+1}\right)\right] \\
0 \leqslant u_{k} \leqslant x_{k} \\
f_{n+1}\left(x_{n+1}\right)=0
\end{array}\right.
$$

2. Negative-sequence recursive model under the objective of cost minimization of commercial banks.

If the state of the terminal stage $\mathrm{x}_{\mathrm{n}+1}$ is given, then the model can be constructed by using method of negative-sequence recursion. We define $f_{k}\left(x_{k+1}\right)$ as the terminal state $x_{k+1}$ of the stage of $k$. The optimal criterion function from the beginning to the stage of $\mathrm{k}$ can be defined as:

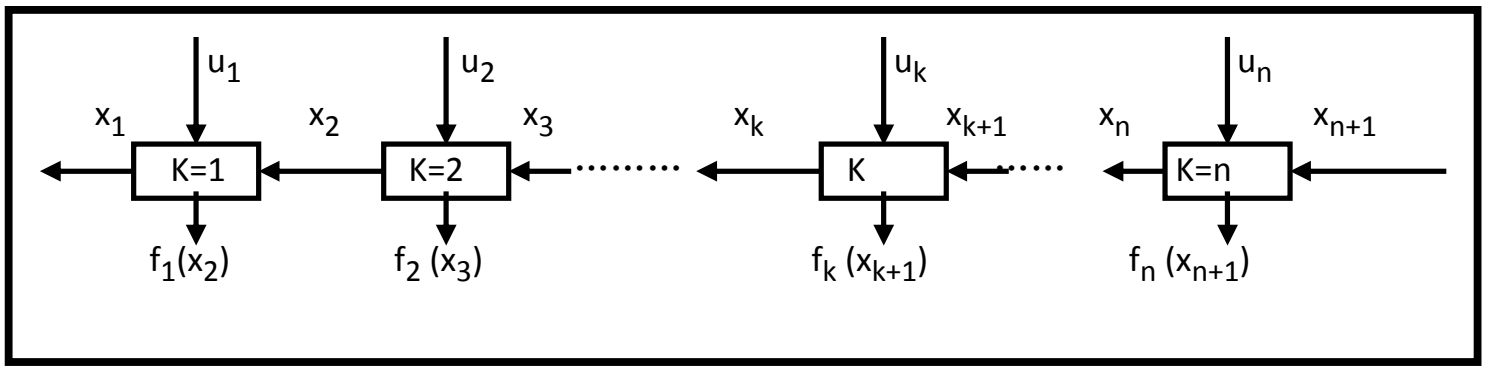

Graph 2. The negative-sequence recursive model of dynamic planning under the objective of cost-minimization of commercial banks

In general, according to real-life scenarios, $\mathrm{f}_{0}\left(\mathrm{x}_{1}\right)$ is the already-known boundary condition. If cost of commercial banks has reached its minimum point (cannot go lower), then $\mathrm{f}_{0}\left(\mathrm{x}_{1}\right)=0$. The dynamic planning equation of cost minimization of commercial banks is: 


$$
\left\{\begin{array}{l}
\mathbf{f}_{\mathbf{k}}\left(\mathbf{x}_{\mathbf{k}+\mathbf{1}}\right)=\min _{\mathrm{q}_{\mathrm{k}} \leqslant \mathrm{u}_{\mathrm{k}} \leqslant \mathrm{v}_{\mathrm{k}}}\left[\mathbf{v}_{\mathbf{k}}\left(\mathbf{x}_{\mathbf{k}+\mathbf{1}}, \mathbf{u}_{\mathbf{k}}\right)+\mathbf{f}_{\mathbf{k}-\mathbf{1}}\left(\mathbf{x}_{\mathbf{k}}\right)\right] \\
\mathbf{f}_{\mathbf{0}}\left(\mathbf{x}_{\mathbf{1}}\right)=\mathbf{0}
\end{array}\right.
$$

III. Case analysis: finding solution for the dynamic planning equation applied to business operation of commercial banks

In real life, equipment allocation is a common decision-making scenario for commercial banks. For example, along with the advancing of modern banking service, automated teller machines (ATM machines) have become more and more popular. However, due to differences in customer visit frequency and consuming habits, actual beneficial result of ATM machines can vary largely from each other. Thus, the supervising organ of each bank branch ought to decide how to efficiently allocate ATM machines to each branch. Assume that commercial bank XXX has purchased ATM machines of $\mathrm{M}$ units from Germany and needs to decide to assign them to branches of $\mathrm{N}$ units. How should the central bank do in order to maximize its annual profit?

1. Question analysis: when the central bank assigns ATM machines of $U_{k}$ units to branch $K$, branch $\mathrm{K}$ can generate profit $\mathrm{g}_{\mathrm{k} \leq} \leq\left(\mathrm{u}_{\mathrm{k}}\right)\left(1_{\leq} \mathrm{k}_{\leq} \mathrm{N}\right)$, assuming that for all machines, $\mathrm{g}_{\mathrm{k}}\left(\mathrm{u}_{\mathrm{k}}\right) \geq 0$. The question can be described as:

\section{$\mathbf{N}$}

$$
\operatorname{Max} Z=\sum g_{k}\left(u_{k}\right)
$$

\section{$\mathrm{K}=1$}

$$
\text { S. t. } \sum_{K=1}^{N} u_{k}=M \quad\left(u_{k} \in Z^{+}\right)
$$

Since $g_{k}\left(u_{k}\right)$ is not a linear function, but probably a non-linear inter programming, it is necessary to transfer it into a process of multi-stage decision-making and construct its dynamic planning model:

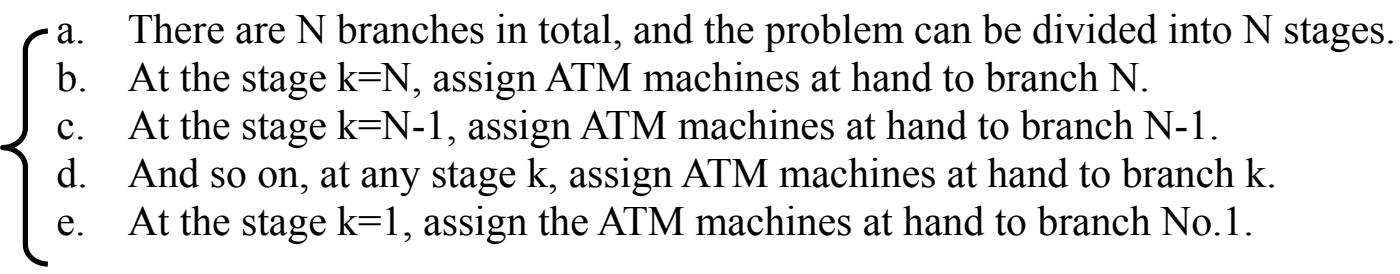

The state-variant $x_{k}$ can be selected as: $x_{k}$ refers to the number of ATM machines owned by the central bank at the beginning of the stage $\mathrm{k}$. Thus, $\mathrm{x}_{1}=\mathrm{M}, \mathrm{x}_{\mathrm{n}+1}=0$.

Decision-variant $u_{k}$ can be selected as: $u_{k}$ refers to the number of ATM machines assigned to branch $\mathrm{k}$ at the stage of $\mathrm{k}\left(0 \leq \mathrm{u}_{\mathrm{k}} \leq \mathrm{x}_{\mathrm{k}}\right)$.

Based on above analysis, the state-transferring equation can be defined as: $\mathrm{x}_{\mathrm{k}+1}=\mathrm{x}_{\mathrm{k}}-\mathrm{u}_{\mathrm{k}}$. The criterion function of stage $\mathrm{k}$ is: $\mathrm{v}_{\mathrm{k}}\left(\mathrm{x}_{\mathrm{k}}, \mathrm{u}_{\mathrm{k}}\right)=\mathrm{g}_{\mathrm{k}}\left(\mathrm{u}_{\mathrm{k}}\right)$.

If we use $f_{k}\left(x_{k}\right)$ to refer to the maximum profit generated when assigning ATM machines of $x_{k}$ units to branch $\mathrm{k}, \mathrm{k}+1, \ldots, \mathrm{N}$, the dynamic planning equation is:

$$
\left\{\begin{array}{l}
\mathrm{f}_{\mathrm{k}}\left(\mathrm{x}_{\mathrm{k}}\right)=\max \left[\mathrm{g}_{\mathrm{k}}\left(\mathrm{u}_{\mathrm{k}}\right)+\mathrm{f}_{\mathrm{k}+1}\left(\mathrm{x}_{\mathrm{k}+1}\right)\right], \quad(\mathbf{k}=\mathbf{N}, \mathrm{N}-\mathbf{1}, \ldots \ldots \mathbf{1}) \\
0 \mathrm{u}_{\mathrm{k}} \leqslant \mathrm{x}_{\mathrm{k}} \\
\mathbf{f}_{\mathrm{N}+\mathbf{1}}\left(\mathbf{x}_{\mathbf{N}+\mathbf{1}}\right)=\mathbf{0}
\end{array}\right.
$$

Then our problem is to find the solution of $f_{1}(M)$. 
2. Based on the data provided, to find optimal solution by using the dynamic planning equation. Assume that we know commercial XXX bank owns 4 ATM machines $(M=4)$, and 3 branches, resource allocation and projected profit $\mathrm{g}_{\mathrm{k}}\left(\mathrm{u}_{\mathrm{k}}\right)$ is as follows:

Table 1: ATM machine allocation plan and projected profit for

\begin{tabular}{|c|c|c|c|}
\hline \multicolumn{4}{|c|}{ Commercial bank XXX } \\
\hline number of ATM $\left(\mathrm{u}_{\mathrm{k}}\right)$ & Branch no.1 & Branch no.2 & Branch no.3 \\
\hline $\mathbf{0}$ & & & $\mathbf{0}$ \\
\hline $\mathbf{1}$ & $\mathbf{0}$ & $\mathbf{0}$ & $\mathbf{3}$ \\
\hline $\mathbf{2}$ & $\mathbf{4}$ & $\mathbf{2}$ & $\mathbf{5}$ \\
\hline $\mathbf{3}$ & $\mathbf{6}$ & $\mathbf{5}$ & $\mathbf{7}$ \\
\hline $\mathbf{4}$ & $\mathbf{7}$ & $\mathbf{6}$ & $\mathbf{8}$ \\
\hline
\end{tabular}

According to Table $1, \mathrm{x}_{1}=4, \mathrm{x}_{4}=4,0 \leq \mathrm{x}_{\mathrm{k}} \leq 4(\mathrm{k}=2,3)$, boundary condition is $\mathrm{f}_{4}\left(\mathrm{x}_{4}\right)=\mathrm{f}_{4}(0)$. Applying the same rule:

When $\mathbf{k}=\mathbf{3}$, since $\mathrm{g}_{\mathrm{k}}\left(\mathrm{u}_{\mathrm{k}}\right)$ is an increasing function, the solution is as follows:

$$
\begin{gathered}
f_{3}\left(x_{3}\right)=\max \left[g_{3}\left(u_{3}\right)+f_{4}(0)\right]=g_{3}\left(x_{3}\right) \\
0 \leq u_{3} \leq x_{3} \\
\left\{\begin{array}{l}
f_{3}(0)=g_{3}(0)=\mathbf{0} ; \\
f_{3}(1)=g_{3}(1)=\mathbf{3} ; \\
f_{3}(2)=g_{3}(2)=\mathbf{5} ; \\
f_{3}(3)=g_{3}(3)=7 ; \\
f_{3}(4)=g_{3}(4)=\mathbf{8} .
\end{array}\right.
\end{gathered}
$$

When $k=2$,

$$
\begin{aligned}
\mathrm{f}_{2}\left(\mathrm{x}_{2}\right)= & \max \left[\mathrm{g}_{2}\left(\mathrm{u}_{2}\right)+\mathrm{f}_{3}\left(\mathrm{x}_{3}\right)\right] \\
= & \max \left[\mathrm{u}_{2} \leq \mathrm{x}_{2}\right. \\
& 0 \leq \mathrm{u}_{2} \leq \mathrm{x}_{2} \\
\mathrm{f}_{2}(0)= & \max \left[\mathrm{g}_{2}\left(\mathrm{u}_{2}\right)+\mathrm{f}_{3}\left(\mathrm{f}_{2}-\mathrm{u}_{2}\right)\right] \\
& 0 \mathrm{u}_{2} \leq 0 \\
= & \mathrm{g}_{2}(0)+\mathrm{f}_{3}(0)=0+0=\mathbf{0} ; \\
\mathrm{f}_{2}(1)= & \max \left[\mathrm{g}_{2}\left(\mathrm{u}_{2}\right)+\mathrm{f}_{3}\left(1-\mathrm{u}_{2}\right)\right] \\
& 0 \leq \mathrm{u}_{2} \leq 1 \\
= & \max \left\{\mathrm{g}_{2}(0)+\mathrm{f}_{3}(1), \mathrm{g}_{2}(1)+\mathrm{f}_{3}(0)\right\} \\
= & \max \{0+3,2+0\}=\mathbf{3} ; \\
\mathrm{f}_{2}(2)= & \max \left[\mathrm{g}_{2}\left(\mathrm{u}_{2}\right)+\mathrm{f}_{3}\left(2-\mathrm{u}_{2}\right)\right] \\
& 0 \leq \mathrm{u}_{2} \leq 2 \\
= & \max \left\{\mathrm{g}_{2}(0)+\mathrm{f}_{3}(2), \mathrm{g}_{2}(1)+\mathrm{f}_{3}(1), \mathrm{g}_{2}(2)+\mathrm{f}_{3}(0)\right\} \\
= & \max \{0+5,2+3,5+0\}=\mathbf{5} ; \\
\mathrm{f}_{2}(3)= & \max \left[\mathrm{g}_{2}\left(\mathrm{u}_{2}\right)+\mathrm{f}_{3}\left(3-\mathrm{u}_{2}\right)\right] \\
& 0 \leq \mathrm{u}_{2} \leq 3 \\
= & \max \left\{\mathrm{g}_{2}(0)+\mathrm{f}_{3}(3), \mathrm{g}_{2}(1)+\mathrm{f}_{3}(2), \mathrm{g}_{2}(2)+\mathrm{f}_{3}(1), \mathrm{g}_{2}(3)+\mathrm{f}_{3}(0)\right\}
\end{aligned}
$$




$$
\begin{aligned}
= & \max \{0+7,2+5,5+3,6+0\}=\mathbf{8} \\
\mathrm{f}_{2}(4)= & \max \left[\mathrm{g}_{2}\left(\mathrm{u}_{2}\right)+\mathrm{f}_{3}\left(4-\mathrm{u}_{2}\right)\right] \\
& 0 \leq \mathrm{u}_{2} \leq 4 \\
= & \max \left\{\mathrm{g}_{2}(0)+\mathrm{f}_{3}(4), \mathrm{g}_{2}(1)+\mathrm{f}_{3}(3), \mathrm{g}_{2}(2)+\mathrm{f}_{3}(2), \mathrm{g}_{2}(3)+\mathrm{f}_{3}(1),\right. \\
& \left.\mathrm{g}_{2}(4)+\mathrm{f}_{3}(0)\right\} \\
= & \max \{0+8,2+7,5+5,6+3,8+0\}=\mathbf{1 0} ;
\end{aligned}
$$

\section{When $\mathrm{K}=\mathbf{1}$,}

$$
\begin{aligned}
\mathrm{f}_{1}\left(\mathrm{x}_{1}\right)= & \max \left[\mathrm{g}_{1}\left(\mathrm{u}_{1}\right)+\mathrm{f}_{2}\left(\mathrm{x}_{2}\right)\right] \\
= & \max \left[\mathrm{u}_{1} \leq \mathrm{x}_{1}\right. \\
& \max \mathrm{u}_{1} \leq \mathrm{x}_{1} \\
\left.\mathrm{f}_{1}\left(\mathrm{u}_{4}\right)=\mathrm{f}_{2}\left(\mathrm{x}_{1}-\mathrm{u}_{1}\right)\right] & \max \left[\mathrm{g}_{1}\left(\mathrm{u}_{1}\right)+\mathrm{f}_{2}\left(4-\mathrm{u}_{1}\right)\right] \\
& 0 \leq \mathrm{u}_{1} \leq 4 \\
= & \max \left\{\mathrm{g}_{1}(0)+\mathrm{f}_{2}(4), \mathrm{g}_{1}(1)+\mathrm{f}_{2}(3), \mathrm{g}_{1}(2)+\mathrm{f}_{2}(2), \mathrm{g}_{1}(3)+\mathrm{f}_{2}(1),\right. \\
& \left.\mathrm{g}_{1}(4)+\mathrm{f}_{2}(0)\right\} \\
= & \max \{0+10,4+8,6+5,7+3,7+0\}=\mathbf{1 2} .
\end{aligned}
$$

Conclusion: Based on above calculation, we get the result that $f_{1}\left(x_{4}\right)=12$ is the maximum profit generated by commercial bank XXX. By analyzing above calculation, we can decide that $\mathrm{f}_{1}\left(\mathrm{x}_{4}\right)=$ 12 is valid, when $\mathrm{u}_{1}=1, \mathrm{u}_{2}=2, \mathrm{u}_{3}=1$. Thus, the central bank should assign these four ATM machines as follows: one machine to branch no.1, two machines to branch no. 2 , and one machine to branch no.3.

\section{References}

[1] DENG Jing-sheng. The new view about reform of the method of pre-service teacher education practice under the background of new curriculum[J]. CAREER HORIZON, 2012, 8(9): 81-83.

[2] Hulman LS.. Knowledge and Teaching: Foundations of the New Reform[J]. Harvard Educational Review, 1987, 57 (1): 135-143.

[3] LIU Xu-dong. On Educational Practice Ability of Normal Students and the Reform of Education and Internship Program[J]. Contemporary Education and Culture, 2011, 3(2): 74-79.

[4] Kato, Takao. The End of Lifetime Employment in Japan: Evidence from National Surveys and Field Research [J]. Journal of the Japanese and International Economies, 2001, 4: 489-514. 